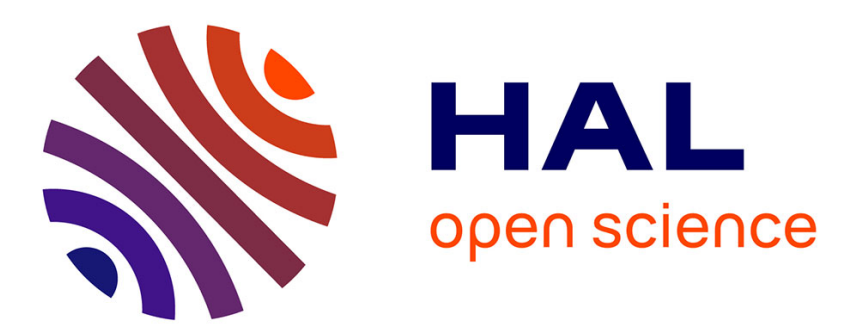

\title{
Ion appearance energies at electron-impact dissociative ionization of sulfur hexafluoride molecule and its fragments
}

\author{
S. Demes, Eugene Yu. Remeta
}

\section{- To cite this version:}

S. Demes, Eugene Yu. Remeta. Ion appearance energies at electron-impact dissociative ionization of sulfur hexafluoride molecule and its fragments. The European Physical Journal D : Atomic, molecular, optical and plasma physics, 2015, 69 (7), pp.168. 10.1140/EPJD/E2015-50636-4 . hal-03038809

\section{HAL Id: hal-03038809 \\ https://hal.science/hal-03038809}

Submitted on 21 Oct 2021

HAL is a multi-disciplinary open access archive for the deposit and dissemination of scientific research documents, whether they are published or not. The documents may come from teaching and research institutions in France or abroad, or from public or private research centers.
L'archive ouverte pluridisciplinaire HAL, est destinée au dépôt et à la diffusion de documents scientifiques de niveau recherche, publiés ou non, émanant des établissements d'enseignement et de recherche français ou étrangers, des laboratoires publics ou privés. 


\section{EPJ D Atomic, Molecular,}

Optical and Plasma Physics $\quad \mathbf{E P J}$.ors

Eur. Phys. J. D (2015) 69: 168

DOI: $10.1140 / \mathrm{epjd} / \mathrm{e} 2015-50636-4$

Ion appearance energies at electron-impact dissociative ionization of sulfur hexafluoride molecule and its fragments

Shandor Sh. Demesh and Eugene Yu. Remeta
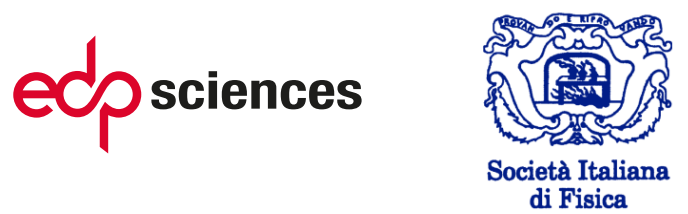

Springer 


\title{
Ion appearance energies at electron-impact dissociative ionization of sulfur hexafluoride molecule and its fragments ${ }^{\star}$
}

\author{
Shandor Sh. Demesh ${ }^{\mathrm{a}}$ and Eugene Yu. Remeta \\ Institute of Electron Physics, National Academy of Sciences of Ukraine, 88017 Uzhgorod, Ukraine
}

Received 28 August 2014 / Received in final form 14 January 2015

Published online 7 July 2015 - (c) EDP Sciences, Società Italiana di Fisica, Springer-Verlag 2015

\begin{abstract}
Theoretical analysis of appearance energies for $\mathrm{SF}_{k}^{+}(k=0-n)$ ion fragments of $\mathrm{SF}_{6}$ molecule as well as $\mathrm{F}^{+}$and $\mathrm{F}_{2}^{+}$ions at electron-impact dissociative ionization of $\mathrm{SF}_{n}(n=1-6)$ molecules is presented. Theoretical methods of GAMESS software package were used to calculate the total energies of neutral and charged molecular and atomic fragments. The dissociative ionization process is concluded to occur via repulsive highly-excited electronic states of the $\mathrm{SF}_{6}$ molecule and its fragments, due to which the observed appearance energies exceed the theoretical values. The electron binding energies on the molecular orbitals in the $\mathrm{SF}_{6}$ molecule are compared with the ion fragment appearance energies.
\end{abstract}

\section{Introduction}

The appearance energy $E_{\mathrm{AP}}$ of an ionic fragment at the electron-impact dissociative ionization of a molecule is equal to the energy required for its formation in this process. The energy $E_{\mathrm{AP}}$ will be minimal if the final products (atoms, molecules, atomic and molecular ions) are in the ground state and have zero kinetic energies. Since the incident electron energy exceeds the ionization potential of the corresponding molecular fragment, the process of dissociative ionization proceeds via highly-excited electronic states of the initial molecule. Hence, this reaction takes place at the threshold of two complicated processes - ionization and dissociation.

The effective simultaneous progress of high-excitation and dissociation processes is possible at a strong correlation of the electronic and atomic motion types for the excited molecule. In other words, the dissociative ionization is a result of interaction of the excited electronic and vibrational states. The difference between electronic and atomic types of motion would be very important, when the molecule achieves high energy from the collision, which leads to dissociation of atoms and to formation of ionic fragments. While measuring $E_{\mathrm{AP}}$ one should determine the states of all the reaction products. Registration of solely the molecular ion fragment enables one to find the energy which is in general determined by the states of the final products obtained in the most probable processes. Note that atomic and molecular reaction products can be in excited states, "couple" to each other as well as form

\footnotetext{
* Contribution to the Topical Issue "Elementary Processes with Atoms and Molecules in Isolated and Aggregated States", edited by Friedrich Aumayr, Bratislav Marinkovic, Stefan Matejcik, John Tanis and Kurt H. Becker.

${ }^{a}$ e-mail: demesh.shandor@gmail.com
}

negative ions. Formation of such ions - i.e. the ion-pair formation process - is possible when the atoms and molecular fragments have large electron affinity. Excitation of the reaction products results in an increase of $E_{\mathrm{AP}}$ while any type of coupling of the particles in the finite states leads to its decrease.

Note here that all the excited electronic states of the $\mathrm{SF}_{6}$ molecule are non-binding and repulsive while the ground and excited electronic states of the $\mathrm{SF}_{6}^{+}$ion are unstable and rapidly (within several picoseconds) dissociate in a channel: $\mathrm{SF}_{6}^{+} \rightarrow \mathrm{SF}_{5}^{+}+\mathrm{F}$ (see Ref. [1]). Therefore, the process of dissociative ionization at the electronimpact excitation of the $\mathrm{SF}_{6}$ molecule can possess specific features. Besides, this should also affect the appearance energies of the ion fragments of the molecule.

The importance of the $\mathrm{SF}_{6}$ molecule studies from the fundamental and application point of view as well as the success achieved in the studies of its structure and various processes of interaction with an electron are well shown in reference [1]. It is shown there that the electron-impact dissociative ionization process becomes significant beginning from the energies of $\sim 16 \mathrm{eV}$, resulting in an appearance of $\mathrm{SF}_{k}^{+}(k=1,3,4,5)$ ion fragments and $\mathrm{F}^{+}$ions. However, neither the data, nor the analysis of the appearance energies for the $\mathrm{SF}_{k}^{+}$ion fragments as well as $\mathrm{F}^{+}$and $\mathrm{F}_{2}^{+}$ions are reported in reference [1].

The appearance energy of a $\mathrm{SF}_{k}^{+}$fragment of the $\mathrm{SF}_{6}$ molecule according to the reaction

$$
e+\mathrm{SF}_{6} \rightarrow \mathrm{SF}_{k}^{+}+2 e+n \mathrm{~F}, \quad n=6-k,
$$

can be determined as follows:

$$
\begin{aligned}
E_{\mathrm{AP}}\left[\left(\mathrm{SF}_{k}^{+}-n \mathrm{~F}\right) / \mathrm{SF}_{6}\right] & =E_{\mathrm{t}}\left(\mathrm{SF}_{k}^{+}\right)+n E_{\mathrm{t}}(\mathrm{F})-E_{\mathrm{t}}\left(\mathrm{SF}_{6}\right) \\
& =D\left[\left(\mathrm{SF}_{k}-n \mathrm{~F}\right) / \mathrm{SF}_{6}\right]+I\left(\mathrm{SF}_{k}\right) .
\end{aligned}
$$


Here the quantities $E_{\mathrm{t}}, D$, and $I$ in equation (2) are the total energy of the minimum of the electronic state with the molecular vibrational energy $G_{\mathrm{v}}$ as well as the energies of dissociation and ionization, respectively. Thus, the appearance energy of $\mathrm{SF}_{k}^{+}$fragments at the dissociative ionization of the $\mathrm{SF}_{6}$ molecule equals the sum of the binding energies of $n$ fluorine atoms within the molecule and the ionization potential of the $\mathrm{SF}_{k}$ fragment. In this case, at the ionization of the $\mathrm{SF}_{6}$ molecule $(k=6)$ the fluorine atoms are not detached $(n=0)$ and the energy received by the molecule is minimal. The appearance of the sulfur ion $(k=0)$ corresponds to the detachment of all fluorine atoms $(n=6)$ which is possible when the $\mathrm{SF}_{6}$ molecule receives the maximal energy value from the incident electron.

Here we report on the results of ab initio calculations of the appearance energy $E_{\mathrm{AP}}$ of the ions at the electronimpact dissociative ionization of the $\mathrm{SF}_{6}$ molecule. The available experimental $E_{\mathrm{AP}}$ data are considered, some of them being compared with calculated values.

\section{Model and method}

In order to obtain the ground state total energies for the molecules, atoms, and ions, the GAMESS software [2] based on the density functional theory [3] was used, running on a Linux cluster with a high level of parallelization. The calculations were performed using two types of hybrid exchange-correlation functionals from the generalized gradient approximation (GGA) - B3LYP [4] and B3PW91 [5]. Both hybrid functionals include Hartree-Fock-type (20\%) and Slater-type (80\%) exchange, while the electron correlation in the case of B3LYP is described by the Lee-YangParr (LYP) functional [6] and in the case of B3PW91 it is described by the Perdew-Wang (PW91) functional [7] (see also Ref. [8]).

The total energies of all the molecules under investigation were determined in two multiplicity states, among which the one with the lower energy was chosen. The $\mathrm{SF}_{6}$ molecule structure was optimized using the quadratic approximation algorithm [9], without the account of the symmetry effect. For the initial geometry, the minimal interatomic distances were given. Once the optimized equilibrium geometry of the $\mathrm{SF}_{6}$ molecule having been obtained, two types of calculations were performed: vertical and adiabatic energy characteristics of the $\mathrm{SF}_{k}$ fragments were determined.

To calculate the adiabatic characteristics, the equilibrium geometries of the $\mathrm{SF}_{k}$ and $\mathrm{F}_{2}$ molecules were as well determined in the course of the geometry optimization using the quadratic approximation algorithm. The above characteristics were found as the differences between the total energies of the relaxed states of the neutral and the ionized systems. The vertical values are defined as an energy difference between the initial $\mathrm{SF}_{6}$ molecule and those $\mathrm{SF}_{k}^{+}$ionic fragments, the structure of which (the bond distances, angles, etc.) was derived from the optimized structure of the $\mathrm{SF}_{6}$ molecule, but without $(6-k)$ number of fluorine atoms. Hence, we state that the structure of the ionic fragments is not relaxed.

The experimental and the calculated adiabatic values of the electron affinities $E_{\mathrm{a}}$, ionization potentials $I$, and the dissociation energies $D$ are compared in Table 1 . For the molecules the total energy of vibrations $G_{\mathrm{v}}$ is taken into account. The ionization potential value $I\left(\mathrm{SF}_{6}\right)$ is taken from reference [81] in [1], where the photoelectron spectroscopy method was applied for its determination (see also the discussion about the $\mathrm{SF}_{6}^{+}$ion measurements in Ref. [1]). In general, there is a fair agreement between the above data. The calculated vertical values are, in general, somewhat above the adiabatic data. The $E_{\mathrm{a}}, I$, and $D$ energy values are rather sensitive to the quality of account of the correlation interaction between the electrons in the atoms and ions. As one can see, this interaction is rather well taken into account by the GAMESS methods for $\mathrm{F}$ and $\mathrm{S}$ atoms and for $\mathrm{F}_{2}$ and $\mathrm{SF}_{k}$ molecules, however the agreement of the values of $E_{\mathrm{a}}\left(\mathrm{SF}_{6}\right)$ and $I\left(\mathrm{SF}_{3}\right)$ is very poor, compared with the experimental data. Thus, the GAMESS calculation data can be quite successfully used for the analysis of the fragment appearance energies. Hereinafter the data from Table 1 are used for the corresponding estimations.

\section{Results and discussion}

The $E_{\mathrm{AP}}$ of the ion fragments can be well determined by measuring the partial yield cross sections of the $\mathrm{SF}_{k}^{+}$ fragments or $\mathrm{F}^{+}$and $\mathrm{S}^{+}$atomic ions, as it was made in references [23-25] (see also [1] and references therein).

\subsection{Appearance energies of the $\mathrm{SF}_{k}^{+}$ion fragments}

The values of the appearance energies $E_{\mathrm{AP}}^{\mathrm{th}}$ of $\mathrm{SF}_{k}^{+}$ions calculated according to equation (1) with the account of the vibrational energies $G_{\mathrm{V}}\left(\mathrm{SF}_{6}\right)$ and $G_{\mathrm{V}}\left(\mathrm{SF}_{k}^{+}\right)$are shown in Table 2. In this table the ionization potentials $I\left(\mathrm{SF}_{\ell}\right)$ are used as appearance energies $E_{\mathrm{AP}}\left(\mathrm{SF}_{\ell}^{+} / \mathrm{SF}_{\ell}\right)$. The average value of the binding energy $E_{\mathrm{b}}$ for a fluorine atom

$$
\begin{array}{r}
E_{\mathrm{b}}(\mathrm{F})=\left[E_{\mathrm{AP}}\left(\mathrm{SF}_{k}^{+}-(n-k) \mathrm{F} / \mathrm{SF}_{n}\right)-I\left(\mathrm{SF}_{k}\right)\right] /(n-k), \\
k<n,
\end{array}
$$

is given in parentheses and is obtained using the experimental and theoretical values of $E_{\mathrm{AP}}$ and $I\left(\mathrm{SF}_{k}\right)$. This energy slightly differs for different molecules. In the case of appearance of the $\mathrm{SF}_{5}^{+} / \mathrm{SF}_{6}$ ion, the binding energy $E_{\mathrm{b}}(\mathrm{F})$, according to the experimental data, is within the interval 4.3-5.9 eV. These values are close to the experimental dissociation energies $D\left(\mathrm{SF}_{5}-\mathrm{F} / \mathrm{SF}_{6}\right) 3.38$ [17], $3.9 \pm 0.15$ [18], $4.1 \pm 0.13 \mathrm{eV}[19]$ and to our calculated data (see Tab. 1).

From Table 2 one can see that the experimental values $E_{\mathrm{AP}}^{\exp }[23]$ systematically exceed the calculated $E_{\mathrm{AP}}^{\text {th }}$ values. With the decreasing number of the detached fluorine atoms (i.e. for large $k$ and at a small value of the energy transferred to the $\mathrm{SF}_{6}$ molecule) the difference between 
Table 1. Calculated adiabatic and experimental energy characteristics of the $\mathrm{F}, \mathrm{S}$ atoms and $\mathrm{F}_{2}, \mathrm{SF}_{k}(k=1-6)$ molecules.

\begin{tabular}{|c|c|c|c|}
\hline \multirow{2}{*}{ Energy characteristics } & \multicolumn{2}{|c|}{ Calculated values, eV } & \multirow{2}{*}{ Experimental values, eV } \\
\hline & B3LYP & B3PW91 & \\
\hline \multicolumn{4}{|c|}{$\mathrm{F}$} \\
\hline$E_{\mathrm{a}}$ & 3.355 & 3.317 & $3.4[10]$ \\
\hline$E_{\text {exc }}$ & - & - & $\begin{array}{c}\mathrm{F}\left(2 p^{5}{ }^{2} \mathrm{P}_{3 / 2}^{\mathrm{o}}\right): 0.05[10] \\
\mathrm{F}\left(2 p^{4} 3 s{ }^{4} \mathrm{P},{ }^{2} \mathrm{P}\right): 12.70-13.03[10]\end{array}$ \\
\hline$I$ & 17.65 & 17.61 & $17.423[10]$ \\
\hline \multicolumn{4}{|c|}{$\mathrm{F}_{2}$} \\
\hline$E_{\mathrm{a}}$ & 3.609 & 3.498 & $2.96[10]$ \\
\hline$E_{\text {exc }}$ & - & - & $\approx 2\left(\right.$ for $\left.\mathrm{Cl}_{2}, \mathrm{Br}_{2}, \mathrm{I}_{2}\right)[10]$ \\
\hline$I$ & 15.62 & 15.59 & $15.686[10]$ \\
\hline$D\left(2 \mathrm{~F} / \mathrm{F}_{2}\right)$ & 1.51 & 1.52 & $1.38[10] ; 1.63[11]$ \\
\hline$G_{\mathrm{V}}, 0^{\circ} \mathrm{K}$ & \multicolumn{2}{|c|}{0.067} & $\sim 0.055[10] ; 0.0565[12]$ \\
\hline \multicolumn{4}{|r|}{ 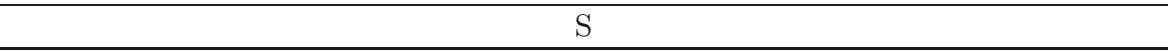 } \\
\hline$E_{\mathrm{a}}$ & 2.129 & 2.157 & $2.077[10]$ \\
\hline$E_{\text {exc }}\left(\mathrm{S}^{+}\right)$ & - & - & $\begin{aligned} \mathrm{S}^{+}\left(3 p^{3}{ }^{2} \mathrm{D}^{\mathrm{o}},{ }^{2} \mathrm{P}^{\mathrm{o}}\right) & : 1.84-3.05[10] \\
\mathrm{S}^{+}\left(3 s 3 p^{4}{ }^{4} \mathrm{P}\right) & : \approx 9.9[10]\end{aligned}$ \\
\hline$I$ & 10.49 & 10.51 & $10.36[10]$ \\
\hline \multicolumn{4}{|c|}{$\mathrm{SF}_{k}$} \\
\hline$I\left(\mathrm{SF}_{6}\right)$ & 14.78 & 14.84 & $15.69 \pm 0.05$ (see Ref. [81] in [1]) \\
\hline$E_{\mathrm{a}}\left(\mathrm{SF}_{6}\right)$ & 2.52 & 2.23 & $1.06[1,13] ; 0.65[10]$ \\
\hline$G_{\mathrm{v}}\left(\mathrm{SF}_{6}\right)$ & \multicolumn{2}{|c|}{0.558} & - \\
\hline$I\left(\mathrm{SF}_{5}\right)$ & 10.41 & 10.32 & $\begin{aligned} 10.5 \pm & 0.1[14] ; 9.6[15] \\
& 11.20[16]\end{aligned}$ \\
\hline$D\left(\mathrm{SF}_{5}-\mathrm{F} / \mathrm{SF}_{6}\right)$ & 3.69 & 3.84 & $\begin{array}{c}3.38[17] ; 3.9 \pm 0.15[18] \\
4.1 \pm 0.13[19]\end{array}$ \\
\hline$G_{\mathrm{V}}\left(\mathrm{SF}_{5}\right)$ & \multicolumn{2}{|c|}{0.400} & - \\
\hline$I\left(\mathrm{SF}_{4}\right)$ & 11.94 & 11.88 & $\begin{array}{c}12.03 \pm 0.05[14] ; 11.69[15] \\
12.08 \pm 0.10[17]\end{array}$ \\
\hline$D\left(\mathrm{SF}_{4}-2 \mathrm{~F} / \mathrm{SF}_{6}\right)$ & 5.08 & 5.37 & - \\
\hline$G_{\mathrm{v}}\left(\mathrm{SF}_{4}\right)$ & \multicolumn{2}{|c|}{0.310} & - \\
\hline$I\left(\mathrm{SF}_{3}\right)$ & 8.88 & 8.01 & $11.0 \pm 1.0[16] ; 8.18 \pm 0.07[20]$ \\
\hline$D\left(\mathrm{SF}_{3}-3 \mathrm{~F} / \mathrm{SF}_{6}\right)$ & 8.58 & 9.79 & - \\
\hline$G_{\mathrm{v}}\left(\mathrm{SF}_{3}\right)$ & \multicolumn{2}{|c|}{0.162} & - \\
\hline$I\left(\mathrm{SF}_{2}\right)$ & 10.16 & 10.17 & $\begin{array}{l}10.08[14] ; 11.8[21] \\
10.29 \pm 0.10[22]\end{array}$ \\
\hline$D\left(\mathrm{SF}_{2}-4 \mathrm{~F} / \mathrm{SF}_{6}\right)$ & 10.95 & 11.38 & - \\
\hline$G_{\mathrm{v}}\left(\mathrm{SF}_{2}\right)$ & \multicolumn{2}{|c|}{0.124} & - \\
\hline$I(\mathrm{SF})$ & 10.23 & 10.26 & $10.09[14]$ \\
\hline$D\left(\mathrm{SF}-5 \mathrm{~F} / \mathrm{SF}_{6}\right)$ & 14.51 & 15.00 & - \\
\hline$G_{\mathrm{V}}(\mathrm{SF})$ & \multicolumn{2}{|c|}{0.052} & $0.052[12]$ \\
\hline$D\left(\mathrm{~S}-6 \mathrm{~F} / \mathrm{SF}_{6}\right)$ & 18.00 & 18.49 & - \\
\hline$D(\mathrm{~S}-\mathrm{F} / \mathrm{SF})$ & 3.49 & 3.49 & $3.5[10]$ \\
\hline
\end{tabular}

the experimental and the theoretical data rapidly decreases. Numerous experimental data in appearance $E_{\mathrm{AP}}^{\mathrm{exp}}$ and binding energies $E_{\mathrm{b}}$ in general agree with each other fairly well; however, the channels of the dissociative ionization process often remain unknown. The existing differences in the measured energies of appearance of some $\mathrm{SF}_{k}^{+}$ions are mostly related to the specific details of the experimental techniques.
Vertical values of the appearance energies are somewhat higher than the adiabatic values. For the appearance of $\mathrm{SF}_{k}^{+}$fragments from the $\mathrm{SF}_{6}$ molecule this increment increases with $k$ : from $0.07 \mathrm{eV}(k=1)$ to $0.64 \mathrm{eV}(k=3)$ and further to the values of $0.82 \mathrm{eV}(k=4)$ and $1.75 \mathrm{eV}$ $(k=5)$ (see Fig. 1 hereafter).

Figure 1 shows the experimental and calculated appearance energies $E_{\mathrm{AP}}$ for the $\mathrm{SF}_{k}^{+}$fragments from the 
Table 2. Appearance energies of $\mathrm{SF}_{k}^{+}$fragments from the $\mathrm{SF}_{\ell}(\ell=0-6)$ molecules.

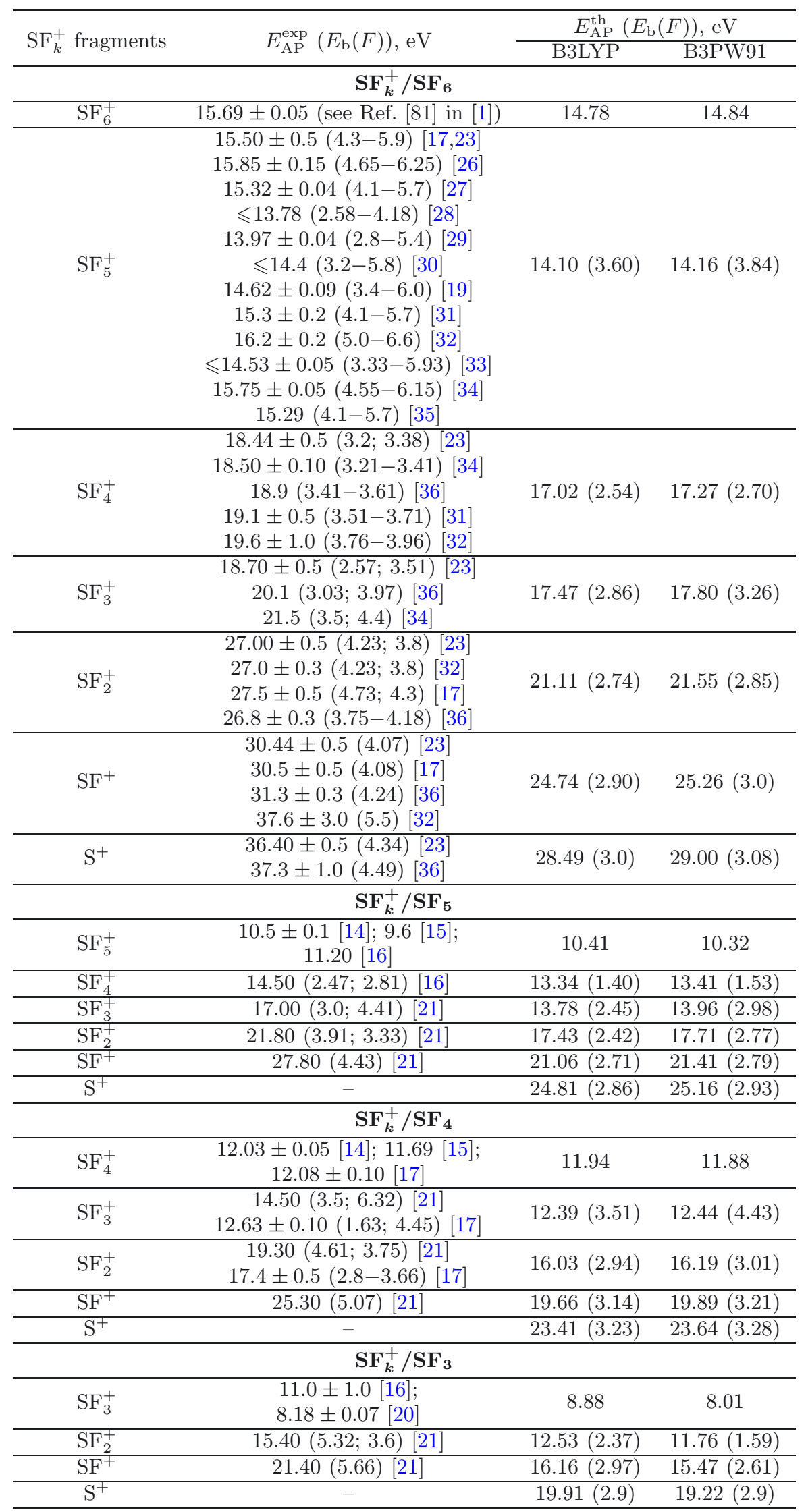


Table 2. continued.

\begin{tabular}{cccc}
\hline \multicolumn{5}{c}{$\mathbf{S F}_{\boldsymbol{k}}^{+} / \mathbf{S F}_{\mathbf{2}}$} \\
\hline $\mathrm{SF}_{2}^{+}$ & $\begin{array}{c}10.08[14] ; 11.8[21] ; \\
10.29 \pm 0.10[22]\end{array}$ & 10.16 & 10.17 \\
\hline $\mathrm{SF}^{+}$ & $\begin{array}{c}18.80(8.71)[21] \\
13.95 \pm 0.10(3.86)[22]\end{array}$ & $13.80(3.57)$ & $13.88(3.62)$ \\
\hline $\mathrm{S}^{+}$ & \multicolumn{4}{c}{$17.55(3.53)$} & $17.63(3.56)$ \\
\hline \multicolumn{5}{c}{$\mathbf{S F}_{\boldsymbol{k}}^{+} / \mathbf{S F}$} \\
\hline $\mathrm{SF}^{+}$ & $10.09[14]$ & 10.23 \\
\hline $\mathrm{S}^{+}$ & \multicolumn{4}{c}{$13.98(3.49)$} & $14.01(3.5)$ \\
\hline \multicolumn{5}{c}{$\mathbf{S}_{\boldsymbol{k}}^{+} / \mathbf{S}$} \\
\hline $\mathrm{S}^{+}$
\end{tabular}

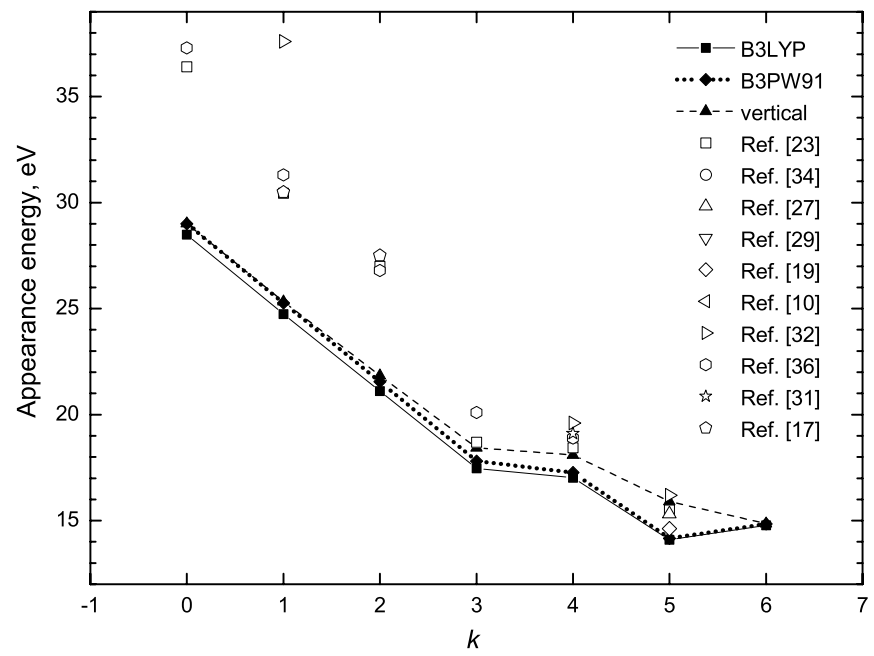

Fig. 1. Appearance energy $E_{\mathrm{AP}}\left(\mathrm{SF}_{k}^{+} / \mathrm{SF}_{6}\right)$ as a function of the remaining fluorine atoms $k(k \leqslant 6)$ in the final fragment $\mathrm{SF}_{k}^{+}$. For $k=6$ the calculated and experimental values of the ionization potential of the $\mathrm{SF}_{6}$ molecule are shown.

$\mathrm{SF}_{6}$ molecule (see Tab. 2) as functions of the number of the remaining fluorine atoms $k$. The calculated values are given for the reaction of the type of equation (1), i.e. for the appearance energies in the case when the reaction products are in the ground state. As one can see, the behaviour of the experimental and the calculated appearance energies is qualitatively similar - they decrease with $k$. However, there is a systematic increment of the experimental data over the theoretical values. It can also be seen that for $k \leqslant 3$ the monotonous behaviour of the experimental $E_{\mathrm{AP}}^{\exp }\left(\mathrm{SF}_{k}^{+} / \mathrm{SF}_{6}\right)$ and the theoretical $E_{\mathrm{AP}}^{\text {th }}\left(\mathrm{SF}_{k}^{+}-(6-k) \mathrm{F} / \mathrm{SF}_{6}\right)$ appearance energies is characterized by a rapid decrease with $k$. For $k \geqslant 3$ this energy decrease with $k$ is less pronounced and the theoretical values are close to the experimental data.

Figures 2 and 3 show the behaviour of experimental and calculated adiabatic appearance energies for the $\mathrm{SF}^{+}$ and $\mathrm{SF}_{2}^{+}$ion fragments depending on the number $\ell$ of fluorine atoms in the initial $\mathrm{SF}_{\ell}$ fragment (see Tab. 2). It can also be seen that the behaviour of the above appearance energies is qualitatively similar as well; however, there is

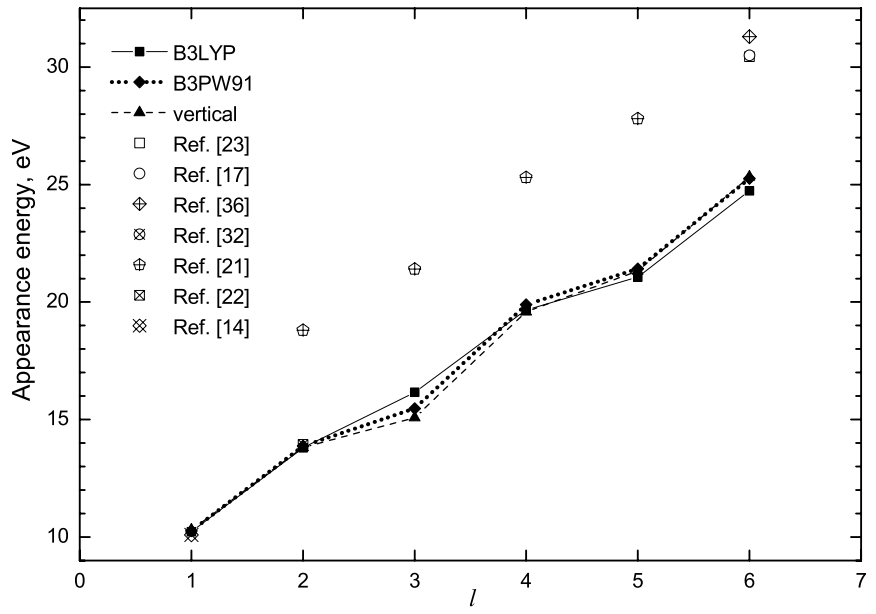

Fig. 2. Appearance energy $E_{\mathrm{AP}}\left(\mathrm{SF}^{+} / \mathrm{SF}_{\ell}\right)$ as a function of the number $\ell$ of fluorine atoms in the initial $\mathrm{SF}_{\ell}$ molecule. For $\ell=1$ the calculated and experimental values of the ionization potential of the SF molecule are shown.

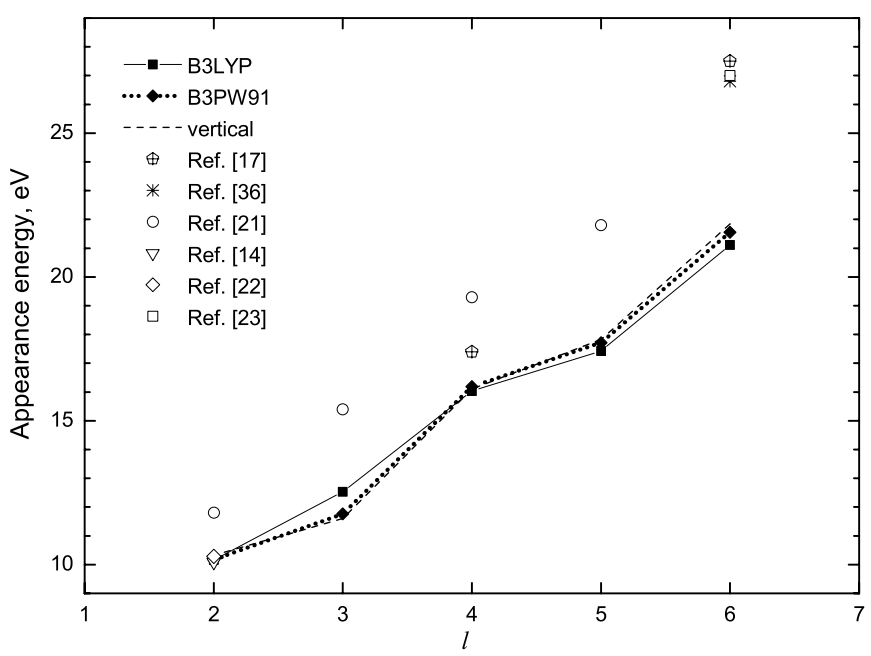

Fig. 3. Appearance energies $E_{\mathrm{AP}}\left(\mathrm{SF}_{2}^{+} / \mathrm{SF}_{\ell}\right)$ versus the number of fluorine atoms $\ell$ in the initial $\mathrm{SF}_{\ell}$ molecule. For $\ell=2$ the calculated and experimental values of the ionization potential of the $\mathrm{SF}_{2}$ molecule are shown. 
Table 3. Appearance energies of $\mathrm{F}^{+}$and $\mathrm{F}_{2}^{+}$fragments from the $\mathrm{SF}_{\ell}$ molecules.

\begin{tabular}{cccc}
\hline \multirow{2}{*}{$\mathrm{SF}_{\ell}$ molecules } & \multirow{2}{*}{$E_{\mathrm{AP}}^{\exp }\left(E_{\mathrm{b}}(\mathrm{F}) ; E_{\mathrm{b}}\left(\mathrm{F}_{2}\right)\right), \mathrm{eV}$} & \multicolumn{2}{c}{$E_{\mathrm{AP}}^{\mathrm{th}}\left(E_{\mathrm{b}}(\mathrm{F}) ; E_{\mathrm{b}}\left(\mathrm{F}_{2}\right)\right), \mathrm{eV}$} \\
\cline { 3 - 4 } & \multicolumn{3}{c}{$\mathrm{B} 3 \mathrm{LYP}$} \\
\hline $\mathrm{SF}_{6} / \mathrm{SF}_{\ell}$ \\
$\mathrm{SF}_{5}$ & - & $21.49(3.84)$ & $21.61(4.0)$ \\
$\mathrm{SF}_{4}$ & - & $19.13(1.48)$ & $19.22(1.61)$ \\
$\mathrm{SF}_{3}$ & - & $21.30(3.65)$ & $22.18(4.57)$ \\
$\mathrm{SF}_{2}$ & - & $20.05(2.4)$ & $19.24(1.63)$ \\
$\mathrm{SF}$ & - & $21.29(3.64)$ & $21.30(3.69)$ \\
\hline \multicolumn{5}{c}{$\mathrm{F}_{2}^{+} / \mathrm{SF}_{\ell}$} \\
\hline $\mathrm{SF}_{6}$ & $18.0 \pm 1.0(1.85,1.97 ;$ & $19.36(2.63 ; 3.74)$ & $19.61(2.77 ; 4.02)$ \\
$\mathrm{SF}_{5}$ & $2.314)[32]$ & $19.17(2.53 ; 3.55)$ & $20.17(3.05 ; 4.58)$ \\
$\mathrm{SF}_{4}$ & - & $20.09(2.99 ; 4.47)$ & $20.19(3.06 ; 4.6)$ \\
$\mathrm{SF}_{3}$ & - & $20.07(2.98 ; 4.45)$ & $19.31(2.62 ; 3.72)$ \\
$\mathrm{SF}_{2}$ & - & $21.21(3.55 ; 5.59)$ & $21.23(3.58 ; 5.64)$ \\
\hline
\end{tabular}

also a systematic increment of the experimental data over the theoretical $E_{\mathrm{AP}}^{\mathrm{th}}$ values. The larger is the number of the fluorine atoms detached, the higher is the increment.

The appearance energies of other fragments are characterized by a similar behaviour. For example, the behaviour of the appearance energies of $\mathrm{S}^{+}$ions from the $\mathrm{SF}_{\ell}$ molecules is a monotonously increasing function of $\ell$ : from $\sim 10.5 \mathrm{eV}(\ell=0)$ and $\sim 14 \mathrm{eV}(\ell=1)$ to $\sim 28.5-29 \mathrm{eV}$ $(\ell=6)$ (see Tab. 2).

All excited electronic states of the $\mathrm{SF}_{6}$ molecule are antibonding [1]. A reason for the underestimated theoretical values of the appearance energies $E_{\mathrm{AP}}\left(\mathrm{SF}_{k}^{+}-(\ell-k) \mathrm{F} / \mathrm{SF}_{\ell}\right)$ with respect to the corresponding experimental ones can be a specific feature of excitation of the repulsive (without a minimum) highly-excited electronic states of the $\mathrm{SF}_{\ell}$ molecule in comparison with the excitation of a state possessing a minimum. An ion fragment is formed effectively via the repulsive electronic state of the electronically excited $\mathrm{SF}_{\ell}$ molecules possessing higher energy. On an example of a diatomic molecule, the spatial width of the repulsive electronic state is determined by the similar width of a vibrational level in the initial molecule. The corresponding energy difference is determined by the slope of the electronic state. A higher number of the detached fluorine atoms at the dissociative ionization requires a higher excitation energy, which corresponds to a steeper electronic state and, consequently, to a higher energy difference. This results in an increasing increment of the observed appearance energy over the theoretical value. This excessive energy goes both to the excitation of the reaction products and the increase of their kinetic energy.

In order to excite the electronic state of the ions the following energy is required [37]: $\mathrm{SF}_{4}^{+}-3.17 \mathrm{eV}(A$ and $B$ states) and $3.90 \mathrm{eV}(C$ and $D$ states $) ; \mathrm{SF}_{2}^{+}-5.32 \mathrm{eV}(A)$, $6.12 \mathrm{eV}(B, C), 8.22 \mathrm{eV}(D), 9.22 \mathrm{eV}(C)$. The energy required to excite the $\mathrm{SF}^{+}$ion is not smaller than for the $\mathrm{SF}$ excitation: $3.07 \mathrm{eV}\left(A^{2} \Pi_{3 / 2}\right)$ and $3.14 \mathrm{eV}\left(A^{2} \Pi_{1 / 2}\right)[10]$. About $0.5 \mathrm{eV}$ is required for the formation of an excited $\mathrm{F}_{2}$ molecule (see the energies $E_{\text {exc }}\left(\mathrm{F}_{2}\right)$ and $D\left(2 \mathrm{~F} / \mathrm{F}_{2}\right)$ in Tab. 1).
One more mechanism of the ion fragment appearance can be understood analyzing the binding energies of molecular orbitals in the initial fragments. The ionization energies of an electron from the valence orbitals in the ground state configuration of $\mathrm{SF}_{6}$

$$
\begin{array}{r}
(\text { core })^{22}\left(4 a_{1 \mathrm{~g}}\right)^{2}\left(3 t_{1 \mathrm{u}}\right)^{6}\left(2 e_{\mathrm{g}}\right)^{4}\left(5 a_{1 \mathrm{~g}}\right)^{2}\left(4 t_{1 \mathrm{u}}\right)^{6}\left(1 t_{2 \mathrm{~g}}\right)^{6}\left(3 e_{\mathrm{g}}\right)^{4} \\
{\left[\left(1 t_{2 \mathrm{u}}\right)^{6}\left(5 t_{1 \mathrm{u}}\right)^{6}\right]\left(1 t_{1 \mathrm{~g}}\right)^{6} A_{1 \mathrm{~g}}}
\end{array}
$$

(given in Ref. [1]), are close to the threshold of the processes resulting in the formation of the corresponding $\mathrm{SF}_{k}^{+}$ fragments. Ionization of an electron from the outer orbital $1 t_{1 \mathrm{~g}}$ (with the energy from 15.29 to $16.0 \mathrm{eV}$ ) can result in the formation of $\mathrm{SF}_{5}^{+}$, from the $2 e_{\mathrm{g}}, 3 e_{\mathrm{g}}, t_{2 \mathrm{u}}$ orbitals (18.0 to $19.1 \mathrm{eV})$ - in the formation of $\mathrm{SF}_{4}^{+}$, from the $1 t_{2 \mathrm{~g}}$ orbital $(19.0$ to $20.3 \mathrm{eV})$ - in the formation of $\mathrm{SF}_{3}^{+}$, and from the $a_{1}$ orbital $(26.0$ to $26.8 \mathrm{eV}$ ) - in the formation of $\mathrm{SF}_{2}^{+}$. At the energies 31.0 and $31.3 \mathrm{eV}$ the ionization of the orbital can lead to the formation of $\mathrm{SF}^{+}$fragments while at 37.0 and $37.3 \mathrm{eV} \mathrm{S}^{+}$ions can be formed.

\subsection{Appearance energies of $\mathrm{F}^{+}$and $\mathrm{F}_{2}^{+}$ions}

The values of the calculated appearance energies $E_{\mathrm{AP}}^{\mathrm{th}}$ of the $\mathrm{F}^{+}$ions (the reaction $e+\mathrm{SF}_{\ell} \rightarrow \mathrm{F}^{+}+2 e+\mathrm{SF}_{\ell-1}, \ell=$ $1-6$ ) and $\mathrm{F}_{2}^{+}$ions (the reaction $e+\mathrm{SF}_{\ell} \rightarrow \mathrm{F}_{2}^{+}+2 e+\mathrm{SF}_{\ell-2}$, $\ell=2-6)$ from the $\mathrm{SF}_{\ell}$ fragments of the $\mathrm{SF}_{6}$ molecule are listed in Table 3 . Using the experimental and theoretical values of $E_{\mathrm{AP}}, I$ and $D$ we evaluated the binding energy $E_{\mathrm{b}}$ for the $\mathrm{F}$ atom and $\mathrm{F}_{2}$ molecule from the $\mathrm{SF}_{6}$ molecule and its molecular fragments.

For the case of appearance of $\mathrm{F}^{+}$ions, the binding energy $E_{\mathrm{b}}$ of the fluorine atom

$$
E_{\mathrm{b}}(\mathrm{F})=E_{\mathrm{AP}}\left(\mathrm{F}^{+}-\mathrm{SF}_{n-1} / \mathrm{SF}_{n}\right)-I(\mathrm{~F})
$$

is given in parentheses. The appearance energy $E_{\mathrm{AP}}\left(\mathrm{F}^{+} / \mathrm{SF}\right)=20.923 \mathrm{eV}$ estimated as an enthalpy 
energy from the experimental values of $I(\mathrm{~F})$ and $D(\mathrm{~F}$ $\mathrm{S} / \mathrm{SF}$ ) [10] from Table 1. This value is close to the calculated one. The following values are presented for the appearance energy $\mathrm{E}_{\mathrm{AP}}\left(\mathrm{F}^{+} / \mathrm{SF}_{6}\right)$ (in Refs. $[32,36]$ ): $37.5 \pm 1.0 \mathrm{eV}$ and $35.8 \pm 1.0 \mathrm{eV}$. As one can see, these values are much higher than our calculated ones. For example, in reference [32], the appearance energy was obtained by electron excitation with $45 \mathrm{eV}$ energy, when the intensity of $\mathrm{F}^{+}$ions with $\sim 7.5 \mathrm{eV}$ kinetic energy is nearly equal to zero. The binding energy $E_{\mathrm{b}}(\mathrm{F})$, evaluated according to equation (5) and using the $E_{\mathrm{AP}}\left(\mathrm{F}^{+} / \mathrm{SF}_{6}\right)$ of [32], is also too high: $\sim 18.4-20 \mathrm{eV}$, which highly overestimates the mentioned dissociation energies in Table 1, where $D\left(\mathrm{SF}_{5}-\mathrm{F} / \mathrm{SF}_{6}\right) \sim 3.4,3.9,4.1 \mathrm{eV}$. According to this, $\sim 17 \mathrm{eV}$ energy goes to the excitation of the formed fragments and the $\mathrm{F}^{+}$ion.

For the case of formation of a $\mathrm{F}_{2}^{+}$ion from the $\mathrm{SF}_{\ell}$ fragments, the average value of the binding energy $E_{\mathrm{b}}$ for the fluorine atom

$E_{\mathrm{b}}(\mathrm{F})=\left[E_{\mathrm{AP}}\left(\mathrm{F}_{2}^{+}-\mathrm{SF}_{n-2} / \mathrm{SF}_{n}\right)-I\left(\mathrm{~F}_{2}\right)+D\left(2 \mathrm{~F} / \mathrm{F}_{2}\right)\right] / 2$

and for the fluorine molecule

$$
E_{\mathrm{b}}\left(\mathrm{F}_{2}\right)=E_{\mathrm{AP}}\left(\mathrm{F}_{2}^{+}-\mathrm{SF}_{n-2} / \mathrm{SF}_{n}\right)-I\left(\mathrm{~F}_{2}\right)
$$

is given in parentheses. We note here, that there is no such exceeding in case of appearance of a $\mathrm{F}_{2}^{+}$ion from the $\mathrm{SF}_{6}$ molecule, as it was observed for the $\mathrm{F}^{+}$ion.

We can see, that the experimental values noticeably exceed the theoretical ones in the case of appearance of the $\mathrm{F}^{+}$ion from the $\mathrm{SF}_{6}$ molecule. The appearance of the $\mathrm{F}^{+}$ion is most likely due to the excited repulsive electronic states of the $\mathrm{SF}_{6}^{+}$ion [32]. These experimental data for the appearance of the $\mathrm{F}^{+}$and $\mathrm{F}_{2}^{+}$ions correlated with the threshold excitation energies of neutral $F$ and $F_{2}$ fragments which are formed at the dissociation of $\mathrm{SF}_{6}$ by electron-impact (see Table 22 in Ref. [1]). There is a large number of channels leading to a partial or complete dissociation of $\mathrm{SF}_{6}$.

A possible reason for the experimental appearance energies $E_{\mathrm{AP}}\left(\mathrm{F}^{+}-\mathrm{SF}_{5} / \mathrm{SF}_{6}\right)$ exceeding the theoretical values can be an effective excitation of the repulsive highlyexcited electronic state of the $\mathrm{SF}_{6}$ molecule. In this case the excessive energy goes to the excitation of $\mathrm{F}^{+}$and $\mathrm{F}_{2}^{+}$ions and the electronic states of neutral $\mathrm{SF}_{\ell-1}$ and $\mathrm{SF}_{\ell-2}$ molecules as well as to the increase of the kinetic energy of the reaction products. For example, the $A, B^{\prime}$, and $B$ electronic states of the $\mathrm{SF}_{2}$ molecule have the following excitation energies (eV): 2.24 [38-41], 4.79 [42,43] and $6.75[42,44]$. The excitation energies of $\mathrm{F}^{+}$ions: $\sim 2.5 \mathrm{eV}$ for $2 s^{2} 2 p^{4}{ }^{1} \mathrm{D}_{2}$ and $\sim 5 \mathrm{eV}$ for $2 s^{2} 2 p^{4}{ }^{1} \mathrm{~S}_{0}$ [10]; while the excitation energies of $\mathrm{F}_{2}^{+}$ions: $2.79 \mathrm{eV}$ for the $A$ state [45] and $5.33 \mathrm{eV}$ for the $B$ state [46].

It is also worth noting, that the appearance of an excited $\mathrm{F}^{+}$ion from $\mathrm{SF}_{6}$ most likely occurs along with the $\mathrm{SF}_{5}^{+}$ion in reference [32], i.e. according to the process

$$
e+\mathrm{SF}_{6} \rightarrow \mathrm{SF}_{6}^{+}+2 e \rightarrow \mathrm{SF}_{5}^{+}+\mathrm{F}^{+*}+3 e .
$$

Note that in this case the experimental value $E_{\mathrm{AP}}\left(\mathrm{F}^{+} / \mathrm{SF}_{6}\right) \approx I\left(\mathrm{SF}_{6}\right)+I(\mathrm{~F})+E_{\text {exc }}\left(\mathrm{F}^{+}\right)$(see also [32]).
Similarly to the case of appearance of the $\mathrm{SF}_{k}^{+}$ion fragments (see above), ionization of an electron from the $1 t_{2 \mathrm{~g}}$ orbital (the energy from 19.0 to $20.3 \mathrm{eV}$ ) can also result in the formation of a $\mathrm{F}_{2}^{+}$molecular ion. Likewise, ionization of an electron from the $2 e_{\mathrm{g}}$ orbital (the energy from 39.3 to $40.6 \mathrm{eV}$ [1]) can lead to the appearance of a $\mathrm{F}^{+}$ ion, and from the $3 t_{\mathrm{u}}$ orbital (the energy above $41.2 \mathrm{eV}$ ) - to the formation of a pair of positive ions $-\mathrm{SF}_{k}^{+}$and $\mathrm{F}^{+}$ or $\mathrm{F}_{2}^{+}$. Therefore, one more effective mechanism of dissociative ionization of the $\mathrm{SF}_{6}$ molecule and its fragments by electron-impact can consist in a removal of electrons from the orbitals whose energies are close to the energies of appearance of the ions.

\section{Summary}

Theoretical analysis of appearance energies for various singly charged positive ion fragments at electron-impact dissociative ionization of sulfur hexafluoride molecule and its fragments was performed, based on the GAMESS software calculations.

The qualitative behaviour of the calculated and measured appearance energies of $\mathrm{SF}_{k}^{+}$ion fragments from the $\mathrm{SF}_{6}$ molecule depending on the number $k$ of the remaining fluorine atoms is the same. In a similar way, a good qualitative agreement is observed for the dependences of the calculated and experimental appearance energies of the $\mathrm{SF}_{k}^{+}$fragments from $\mathrm{SF}_{\ell}$ molecule on the final number $k$ and the initial number $\ell$ of fluorine atoms.

The fact that the theoretical values are underestimated with respect to the experimental appearance energies can be explained by a possible effective excitation of the repulsive highly-excited electronic states of the electronically excited $\mathrm{SF}_{6}$ molecule and its molecular fragments. As a result, the final atomic and molecular products of reaction can exist in excited states and possess significant kinetic energies. Another possible mechanism of the molecular ion appearance can be removal of an electron from an energetically suitable molecular orbital in the initial $\mathrm{SF}_{6}$ molecule or its molecular fragments. This mechanism also leads to highly-excited electronic states of these molecules.

A more detailed explanation of the specific features of the ion fragment appearance requires determination of characteristics of the reaction channel final products, namely the kinetic energy, the excited and charged states.

The authors are grateful to A.V. Snegursky, Yu.M. Azhniuk and V.V. Maslyuk for their support and fruitful discussions. One of the authors, Sh. Demesh, acknowledges the Collegium Talentum institution for the financial and professional support of his scientific work. This research was realized in the frames of TÁMOP 4.2.4. A/2-11-1-2012-0001, National Excellence Program "Elaborating and operating an inland student and researcher personal support system". The project was subsidized by the European Union and cofinanced by the European Social Fund. 


\section{References}

1. L.G. Christophorou, J.K. Olthoff, J. Phys. Chem. Ref. Data. 29, 267 (2002)

2. M.W. Schmidt, K.K. Baldridge, J.A. Boatz, S.T. Elbert, M.S. Gordon, J.J. Jensen, S. Koseki, N. Matsunaga, K.A. Nguyen, S. Su, T.L. Windus, M. Dupuis, J.A. Montgomery, J. Comput. Chem. 14, 1347 (1993)

3. W. Kohn, L.J. Sham, Phys. Rev. 140, A1133 (1965)

4. R.H. Hertwig, W. Koch, Chem. Phys. Lett. 268, 345 (1997)

5. A.D. Becke, J. Chem. Phys. 98, 5648 (1993)

6. C. Lee, W. Yang, R.G. Parr, Phys. Rev. B 37, 785 (1988)

7. J.P. Perdew, Y. Wang, Phys. Rev. B 45, 13244 (1992)

8. T.H. Dunning Jr., P.J. Hay, in Methods of Electronic Structure Theory, edited by H.F. Schaefer, 3rd edn. (Plenum Press, New York, 1977)

9. T. Helgaker, Chem. Phys. Lett. 182, 503 (1991)

10. A.A. Radtsig, B.M. Smirnov, in Reference Data on Atoms, Molecules, and Ions (Springer-Verlag, Berlin, 1985)

11. B. de B. Darwent, Bond Dissociation Energies in Simple Molecules, Nat. Stand. Ref. Data Ser., Nat. Bur. Stand. 31. (Washington, 1970)

12. K.K. Irikura, J. Phys. Chem. Ref. Data. 36, 389 (2007)

13. E. Miyoshi, Y. Sakai, S. Miyoshi, J. Chem. Phys. 88, 1470 (1988)

14. S.G. Lias, J.E. Barmess, J.F. Liebman, J.L. Holmes, R.D. Levin, W.G. Mallard, J. Phys. Chem. Ref. Data. Suppl. 17, 861 (1988)

15. S.G. Lias, J.F. Liebman, Ion Energetics Data, NIST Chem. WebBook., ed. by P.J. Linstrom, W.G. Mallard. NIST. Gaithersburg MD. 20899 (retrieved January 31. 2014), http://webbook.nist.gov/cgi/cbook.cgi? $\mathrm{ID}=\mathrm{C} 10546017 \&$ Units $=$ SI\&Mask=20\#Ion-Energetics

16. V. Tarnovsky, H. Deutsch, K.I. Martus, K. Becker, J. Chem. Phys. 109, 6596 (1998)

17. D.L. Hildenbrand, J. Phys. Chem. 77, 897 (1973)

18. T. Kiang, R.C. Estler, R.N. Zare, J. Chem. Phys. 70, 5925 (1979)

19. L.M. Babcock, G.E. Streit, J. Chem. Phys. 74, 5700 (1981)

20. E.R. Fischer, B.L. Kickel, P.B. Armentrout, J. Chem. Phys. 97, 4859 (1992)

21. M. Ito, M. Goto, H. Toyoda, H. Sugai, Contrib. Plasma Phys. 35, 405 (1995)

22. W. Gombler, A. Haas, H. Willner, Z. Anorg. Allg. Chem. 469, 135 (1980)

23. A.N. Zavilopulo, O.B. Shpenik, A.V. Snegursky, F.F. Chipev, V.S. Vukstich, Tech. Phys. Lett. 31, 785 (2005)
24. T. Stanski, B. Adamczyk, Int. J. Mass Spectrom. Ion Phys. 46, 31 (1983)

25. D. Margreiter, G. Walder, H. Deutsch, H.U. Poll, C. Winkler, K. Stephan, T.D. Märk, Int. J. Mass Spectrom. Ion Process. 100, 143 (1990)

26. R.E. Fox, R.K. Curran, J. Chem. Phys. 34, 1595 (1961)

27. K. Mitsuke, S. Suzuki, T. Imamura, I. Koyano, J. Chem. Phys. 93, 8717 (1990)

28. J.A. Stone, W. Wytenberg, J. Int. J. Mass Spectrom. Ion Process. 94, 269 (1989)

29. M. Tichy, G. Javahery, N.D. Twiddy, E.E. Ferguson, Int. J. Mass Spectrom. Ion Process. 79, 231 (1987)

30. R.J. Shul, B.L. Upschulte, R. Passarella, R.G. Keesee, A.W. Castleman, J. Phys. Chem. 91, 2556 (1987)

31. M. Sasanuma, E. Ishiguro, T. Hayaishi, H. Masuko, Y. Morioka, T. Nakajima, M. Nakamura, J. Phys. B. 12, 4057 (1979)

32. B.P. Pullen, J.A.D. Stockdale, Int. J. Mass Spectrom. Ion Phys. 19, 35 (1976)

33. I.G. Simm, C.J. Danby, J.H.D. Eland, P.I.J. Mansell, J. Chem. Soc. 426 (1975)

34. J. Delwiche, Bull. Cl. Sci. Acad. Roy. Belg. 55, 215 (1969)

35. V.H. Dibeler, J.A. Walker, J. Chem. Phys. 44, 4405 (1966)

36. V.H. Dibeler, F.L. Mohler, J. Res. Nat. Bur. Std. 40, 25 (1948)

37. M.E. Jacox, Vibrational and Electronic Energy Levels of Polyatomic Transient Molecules, NIST Chem. WebBook, ed. by P.J. Linstrom, W.G. Mallard, NIST, Gaithersburg MD, 20899 (retrieved April 14, 2014), http://webbook. nist. gov/cgi/cbook. $\operatorname{cgi}$ ? ID=C12528368\&Units=SI\& Mask $=800 \#$ Electronic-Spec

38. R.J. Glinski, Chem. Phys. Lett. 129, 342 (1986)

39. R.J. Glinski, E.A. Mishalanie, J.W. Birks, J. Photochem. 37, 217 (1987)

40. R.J. Glinski, C.D. Taylor, Chem. Phys. Lett. 155, 511 (1989)

41. R.J. Glinski, C.D. Taylor, F.W. Kutzler, J. Phys. Chem. 94, 6196 (1990)

42. Q. Li, J. Shu, Q. Zhang, S. Yu, L. Zhang, C. Chen, X. Ma, J. Phys. Chem. 102, 7233 (1998)

43. Q. Li, Q. Zhang, J. Shu, S. Yu, Q. Song, C. Chen, X. Ma, Chem. Phys. Lett. 305, 79 (1999)

44. R.D. III Johnson, J.W. Hudgens, J. Phys. Chem. 94, 3273 (1990)

45. T.L. Porter, J. Chem. Phys. 48, 2071 (1968)

46. A.B. Cornford, D.C. Frost, C.A. McDowell, J.L. Ragle, I.A. Stenhouse, J. Chem. Phys. 54, 2651 (1971) 